\title{
Exercise Intervention to Improve the Bone Mineral Density and Bone Metabolic Markers as Risk Factors for Fracture in Japanese Subjects with Osteoporosis: a Systematic Review and Meta-analysis of Randomized Controlled Trials
}

\author{
Ryo Tanaka ${ }^{1)}$, Junya Ozawa ${ }^{1)}$, Takuya Umehara ${ }^{2)}$, Nobuhiro Kito ${ }^{1)}$, \\ TAKahiro Yamasaki ${ }^{1)}$, Ayako EnAmi ${ }^{3}$ ) \\ 1) Department of Integrated Rehabilitation, Hiroshima International University: 555-36 Gakuendai, \\ Kurose, Higashi-Hiroshima, Hiroshima 739-2695, Japan.E-mail: r-tanaka@hs.hirokoku-u.ac.jp \\ 2) Department of Rehabilitation, Saiseikai Kure Hospital \\ 3) Faculty of Medicine, Hiroshima University
}

\begin{abstract}
Purpose] Systematic reviews that confirm the positive effect of exercise intervention on fracture risk factors in people with osteoporosis (OP) have included few randomized controlled trials (RCTs) on subjects with OP from Japan, which has the lowest level of obesity among developed countries. We performed a systematic review and meta-analysis of RCTs to investigate the effect of exercise intervention on bone mineral density (BMD) and bone metabolic markers as risk factors in Japanese subjects with OP. [Subjects and Methods] Studies were identified by searching PubMed, CENTRAL, PEDro, CINAHL and Ichushi-Web. We used the Review Manager 5.1 software in accordance with the Preferred Reporting Items for Systematic Reviews and Meta-Analyses Statement protocol (PRISMA). [Results] Three studies (4 exercise groups) were included in our review. No studies showed that the effect of exercise was better significantly than that observed in the control group. Results of pooled data did not show a positive effect of exercise intervention on BMD. [Conclusion] We could not provide high-quality evidence that BMD and bone metabolic markers in Japanese subjects with OP can be improved by exercise intervention.

Key words: Osteoporosis, Exercise, Fracture
\end{abstract}

(This article was submitted Aug. 2, 2012, and was accepted Sep. 4, 2012)

\section{INTRODUCTION}

Osteoporosis (OP) is defined as a disease characterized by low bone mass and micro-architectural deterioration of bone tissue, leading to enhanced bone fragility and a consequent increase in fracture risk ${ }^{1)}$. The most common clinical manifestations of OP are fractures of the hip, vertebrae or wrist. OP-related fractures are responsible for excess mortality and morbidity, chronic pain, reduction in quality of life, admission to long-term care and increased health and social care costs ${ }^{2}$. Bone mineral density (BMD) is an important tool because of its confirmed ability to predict future fracture risk ${ }^{3}$. Bone metabolism is also related to fracture risk $^{4-6)}$. Many meta-analysis and review studies have reported the positive effects of exercise intervention on BMD and OP-related fractures ${ }^{7}{ }^{8}$ ). However, this evidence was obtained from research trials conducted on participants in the US or Europe. Few Japanese subjects with OP were included in these research articles. Among developed countries, Japan has the lowest level of obesity ${ }^{9}$. Low body mass index (BMI) is a substantially important risk factor for all fractures and is largely independent of age and $\operatorname{sex}^{10)}$. We assessed the effect of exercise intervention on fracture risk in Japanese subjects with a lower BMI than that in individuals from the US or Europe. The purpose of our systematic review and meta-analysis was to investigate which exercise interventions are effective in Japanese subjects with OP specifically for the improvement of BMD and bone metabolic markers as risk factors for fracture.

\section{SUBJECTS AND METHODS}

Randomized controlled trials (RCTs) on the efficacy of exercise were included. No publication date or publication status restrictions were imposed. Observational studies, such as cohort studies, were excluded. Participants who had been diagnosed with OP were considered. No age, sex or BMI restrictions were imposed. Trials including individuals scheduled to undergo surgery were excluded from our review because therapeutic exercise cannot be applied to these individuals. Furthermore, subjects who had undergone surgery (e.g., vertebroplasty) were excluded 
from our review. Trials comparing groups with no exercise in Japanese subjects with OP were included. The trials selecting muscle strengthening exercise, aerobic exercise, stretching exercise, tai chi or manual therapy as exercise intervention were included. There were no restrictions with respect to frequency, duration or intensity of exercise. The primary outcome measure was BMD and bone metabolic markers. No restrictions were imposed on the type of radiography used (e.g., dual-energy X-ray absorptiometry) or measurement area (e.g., lumbar).

Studies were identified by searching electronic databases. Searches were performed in PubMed, the Cochrane Central Register of Controlled Trials (CENTRAL), the Physiotherapy Evidence Database (PEDro), the Cumulative Index to Nursing and Allied Health Literature (CINAHL), and Ichushi-Web (a Japanese medical literature database). Publication data was included from studies published up to August 31, 2011. The first author (R.T.) developed and conducted the searches.

We used the following search terms to search all trial registers and databases: osteoporosis, exercise, and exercise therapy. The search strategy consisted of a combination of free text words and Medical Subject Headings (MeSH) terms. Article searches in the PubMed, CINAHL and Ichushi-Web databases were limited to RCTs. Search strategies were peer reviewed as part of the systematic review process. Publication language was not restricted. The search strategy is shown in Table 1.

The risk of bias in the studies included in our review was determined using the PEDro scale ${ }^{11)}$. The PEDro scale contains 10 check items: "random allocation," "concealed allocation," "baseline comparability," "blind subjects," "blind therapists," "blind assessors," "adequate follow-up," "intention-to-treat analysis," "between-group comparisons," and "point estimates and variability."

Since the outcomes consisted of continuous data, the standard mean difference (SMD) was used as the effect measure. The SMD is the difference in mean outcome between groups divided by the standard deviation of the outcome. The SMD and corresponding 95\% confidence intervals $(95 \% \mathrm{CI})$ were calculated for the continuous outcome data. The selection of either a fixed-effect model or a random-effect model was based on examination of statistical heterogeneity between trials.

The inverse variance method was used to synthesize the results using Review Manager version 5.1 (Copenhagen: The Nordic Cochrane Centre, The Cochrane Collaboration, 2011). If a standard deviation (SD) was not given, it could be calculated from the $95 \% \mathrm{CI}$ or the standard error of the mean (SE) values. Positive values indicate that the exercise group improved on average more than the control group. Heterogeneity between trials was examined using the $\chi^{2}$ test and the $l^{2}$ test. The $l^{2}$ test does not inherently depend on the number of studies and is accompanied by an uncertainty interval. A rough guide to interpretation is as follows ${ }^{12)}$ : $0 \%$ to $40 \%$ might not be important; $30 \%$ to $60 \%$ may represent moderate heterogeneity; $50 \%$ to $90 \%$ may represent substantial heterogeneity; $75 \%$ to $100 \%$ represent considerable heterogeneity. In cases of homogeneity, a fixed-effects model was used,
Table 1. Search strategy

\begin{tabular}{ll}
\hline (1) PubMed & \#1 osteoporosis [MeSH Terms] \\
& \#2 exercise [MeSH Terms] \\
& \#3 exercise therapy [MeSH Terms] \\
& $\# 4$ (\#1 AND (\#2 OR \#3)) \\
& Limits: Randomized Controlled Trial \\
\hline (2) CENTRAL & $\# 1$ osteoporosis [MeSH Terms] \\
& \#2 exercise [MeSH Terms] \\
& \#3 exercise therapy [MeSH Terms] \\
& $\# 4$ (\#1 AND (\#2 OR \#3)) \\
\hline (3) PEDro & •Advance search \\
& Therapy: Strength training OR Fitness \\
& training OR Stretching, Mobilisation, \\
& Manipulation, Massage \\
& Title or Abstract: osteoporosis \\
& Method: clinical trial \\
& $\# 1$ osteoporosis [MeSH Terms] \\
& $\# 2$ exercise [MeSH Terms] \\
& $\# 3$ exercise therapy [MeSH Terms] \\
& $\# 4$ (\#1 AND (\#2 OR \#3)) \\
& Limits: Randomized Controlled Trial \\
\hline (4) CINAHL
\end{tabular}

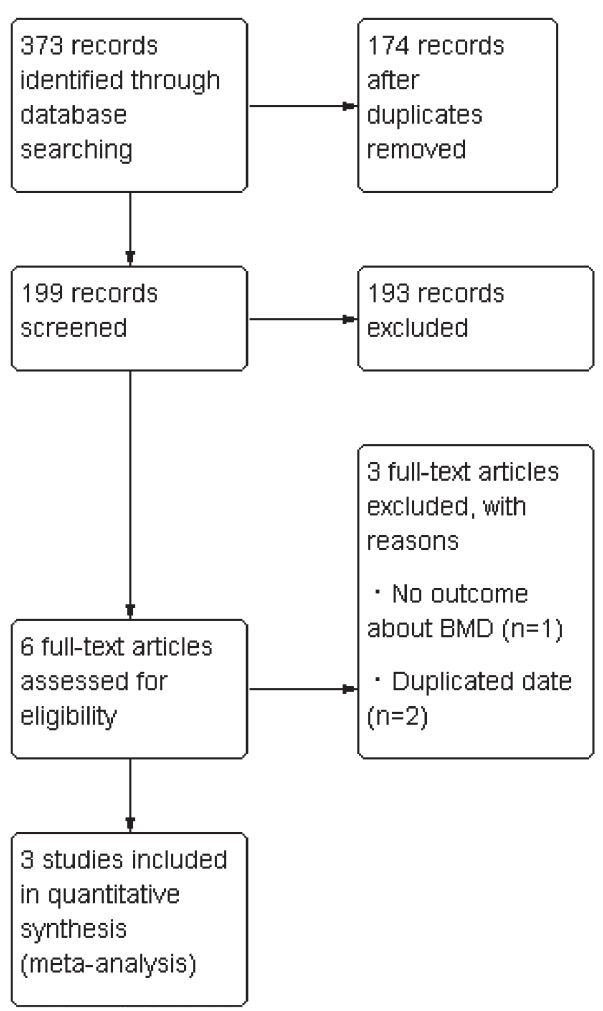

Fig. 1. Search and selection of randomized controlled trials (RCTs)

and in cases of heterogeneity, a random-effects model was used. 
Table 2. Characteristics of participants

\begin{tabular}{|c|c|c|c|c|c|c|c|}
\hline Study & Population & Number & Age (years) & Hight (m) & Weight (kg) & BMI $\left(\mathrm{kg} / \mathrm{m}^{2}\right)$ & $\operatorname{BMD}\left(\mathrm{g} / \mathrm{cm}^{2}\right)$ \\
\hline $\begin{array}{c}\text { Shirado et al. } \\
\text { (1998) }\end{array}$ & $\begin{array}{c}\text { Osteoporotic } \\
\text { postmenopausal } \\
\text { women }\end{array}$ & $\begin{array}{l}\mathrm{E} 1=14 \\
\mathrm{E} 2=14 \\
\mathrm{C}=13\end{array}$ & 59 & (not reported) & (not reported) & (not reported) & $\begin{array}{l}\mathrm{E} 1=0.697(0.050) \\
\mathrm{E} 2=0.673(0.081) \\
\mathrm{C}=0.737(0.065)\end{array}$ \\
\hline $\begin{array}{l}\text { Iwamoto } \\
\text { et al. } \\
(2001)\end{array}$ & $\begin{array}{c}\text { Osteoporotic } \\
\text { postmenopausal } \\
\text { women }\end{array}$ & $\begin{array}{l}E=8 \\
C=20\end{array}$ & $\begin{array}{l}E=65.3(4.7) \\
C=64.9(5.7)\end{array}$ & $\begin{array}{l}E=1.52(0.08) \\
C=1.52(0.06)\end{array}$ & $\begin{array}{l}E=45.5(6.5) \\
C=45.8(4.0)\end{array}$ & $\begin{array}{l}\mathrm{E}=19.7(1.3) \\
\mathrm{C}=19.9(2.1)\end{array}$ & $\begin{array}{l}\mathrm{E}=0.595(0.067) \\
\mathrm{C}=0.611(0.045)\end{array}$ \\
\hline $\begin{array}{l}\text { Iwamoto } \\
\text { et al. } \\
(2005)\end{array}$ & $\begin{array}{c}\text { Osteoporotic } \\
\text { postmenopausal } \\
\text { women }\end{array}$ & $\begin{array}{l}E=25 \\
C=38\end{array}$ & $\begin{array}{l}\mathrm{E}=71.9(8.1) \\
\mathrm{C}=67(5)\end{array}$ & $\begin{array}{l}\mathrm{E}=1.45(0.07) \\
\mathrm{C}=1.46(0.07)\end{array}$ & $\begin{array}{l}\mathrm{E}=45.5(8.6) \\
\mathrm{C}=44.4(8.4)\end{array}$ & $\begin{array}{l}\mathrm{E}=21.6(3.3) \\
\mathrm{C}=20.8(3.3)\end{array}$ & $\begin{array}{l}\mathrm{E}=0.563(0.114) \\
\mathrm{C}=0.569(0.107)\end{array}$ \\
\hline
\end{tabular}

BMI, body mass index; BMD, bone mineral density; E, exercise group; C, control group. One study includes multiple exercises; its groups are shown as E1 and E2 in this table. The standard deviation is shown in parentheses.

Table 3. Characteristics of intervention, outcome and results of the individual studies in our review

\begin{tabular}{|c|c|c|c|c|c|}
\hline Study & Type of exercise & Duration & Frequency & $\begin{array}{l}\text { Relevant } \\
\text { outcome }\end{array}$ & $\begin{array}{l}\text { Results } \\
\text { (comparison between groups) }\end{array}$ \\
\hline $\begin{array}{l}\text { Shirado et al. } \\
\qquad(1998)\end{array}$ & $\begin{array}{l}\text { E1: balance exercise with one leg } \\
\text { E2: balance exercise with one leg, } \\
\text { back extensor strengthening exercise } \\
\text { C: no exercise }\end{array}$ & 12 months & $\begin{array}{l}\text { E1: } 30 \mathrm{sec} / \mathrm{set} \\
\text { more than } 5 \\
\text { times/day }\end{array}$ & BMD & Lumbar BMD: $\mathrm{E} 1=\mathrm{E} 2=\mathrm{C}$ \\
\hline $\begin{array}{l}\text { Iwamoto } \\
\text { et al. } \\
(2001)\end{array}$ & $\begin{array}{l}\text { E: walking, SLR, squatting, abdomi- } \\
\text { nal and back muscle strengthening } \\
\text { exercises } \\
\text { C: no exercise }\end{array}$ & 12 months & 15 repetitions & BMD & Lumbar BMD: $\mathrm{E}=\mathrm{C}$ \\
\hline $\begin{array}{l}\text { Iwamoto } \\
\text { et al. } \\
(2005)\end{array}$ & $\begin{array}{l}\text { E: whole body vibration training } \\
\text { C: no exercise } \\
\text { Both gropus received alendronate }\end{array}$ & 12 months & $\begin{array}{l}4 \text { minutes, once } \\
\text { a week }\end{array}$ & $\begin{array}{l}\text { BMD, bone } \\
\text { metabolic } \\
\text { markers }\end{array}$ & $\begin{array}{l}\text { Lumbar BMD: } \mathrm{E}=\mathrm{C} \\
\text { Urinary NTX: } \mathrm{E}=\mathrm{C} \\
\text { Serum ALP: } \mathrm{E}=\mathrm{C}\end{array}$ \\
\hline
\end{tabular}

BMI, body mass index; NTX, N-terminal telopeptides of type 1 collagen; ALP, alkaline phosphatase; E, exercise group; C, control group. One study includes multiple exercises; its groups are shown as E1 and E2 in this table.

\section{RESULTS}

The search of electronic databases provided 373 citations. After adjusting for duplicates, 199 remained. Of these, 196 studies were discarded because they did not meet the inclusion criteria. Three studies ${ }^{13-15)}$ (4 exercise groups) were included in our review (Fig. 1).

The included studies involved 132 participants (Table 2, 61 exercises and 71 comparisons). In the included studies, the average patient age ranged from 59 years $^{15)}$ to 71.9 years ${ }^{13)}$, and the gender of all participants was female. The average height $\left.{ }^{13}, 14\right)$ ranged from $1.45 \mathrm{~m}$ to $1.52 \mathrm{~m}$; the average body weight $\left.{ }^{13}, 14\right)$ was $45.5 \mathrm{~kg}$; and the $\mathrm{BMI}^{13,14)}$ ranged from $19.7 \mathrm{~kg} / \mathrm{m}^{2}$ to $21.6 \mathrm{~kg} / \mathrm{m}^{2}$; and the lumbar $\mathrm{BMD}^{13,15)}$ ranged from $0.563 \mathrm{~g} / \mathrm{cm}^{2}$ to $0.697 \mathrm{~g} / \mathrm{cm}^{2}$. Characteristics of interventions in each study are shown in Table 3 . The types of exercise used in the 3 studies (4 exercise groups) that measured BMD included whole-body vibration training ${ }^{13)}$, walking $^{14)}$, straight leg raising ${ }^{14)}$, squatting ${ }^{14)}$, trunk and/ or back muscle strengthening exercises $\left.{ }^{14}, 15\right)$ and one-leg balance exercise ${ }^{15)}$. Exercise duration in the included studies was 12 months $^{13-15)}$. Exercise frequency was once a week ${ }^{13)}$ and 5 times a week ${ }^{15)}$. One study ${ }^{14)}$ did not report the exercise frequency. All studies used no exercise for the control group.
Only 1 study $^{13)}$ prescribed alendronate for both the exercise group and the control group. Outcomes measured in each study are shown in Table 3 . All 3 studies $^{13-15)}$ that aimed to improve BMD measured only lumbar BMD. One study ${ }^{13}$ ) measured bone metabolic markers (urinary $\mathrm{N}$-terminal telopeptides of type 1 collagen, urinary NTX; serum alkaline phosphatase, serum ALP).

A summary of the PEDro scores is given in Table 4. Two studies $^{13,14)}$ had a PEDro score of 4 . A PEDro score of 6 was found in 1 study ${ }^{15)}$. No studies concealed allocation or were blinded for subjects, therapist or assessors.

Regardless of final measurement outcome, no studies showed that the effect of exercise was better than that observed in the control group (Table 3 ). We could synthesize the results of BMD data from the three studies. The pooled SMD of the studies can be seen in the forest plots (Fig. 2). The effect of integrating the 4 exercise groups in the 3 studies $^{13-15)}$ that measured lumbar BMD was not significant. In addition, moderate statistical heterogeneity was found, but was not significant $\left(l^{2}=33 \%\right)$.

\section{DISCUSSION}

A review of the Cochrane Review database reported by 
Table 4. Risk of bias within studies

\begin{tabular}{cccccccccccc}
\hline Study & 1 & 2 & 3 & 4 & 5 & 6 & 7 & 8 & 9 & 10 & Total \\
\hline $\begin{array}{c}\text { Shirado et al. } \\
(1998)\end{array}$ & Yes & No & Yes & No & No & No & Yes & Yes & Yes & Yes & 6 \\
\hline $\begin{array}{c}\text { Iwamoto et al. } \\
(2001)\end{array}$ & Yes & No & Yes & No & No & No & No & No & Yes & Yes & 4 \\
\hline $\begin{array}{c}\text { Iwamoto et al. } \\
(2005)\end{array}$ & Yes & No & Yes & No & No & No & No & No & Yes & Yes & 4 \\
\hline
\end{tabular}

PEDro Criteria: (1) Random allocation. (2) Allocation concealed. (3) Groups similar at baseline. (4) Participant blinding. (5) Therapist blinding. (6) Assessor blinding. (7) Measures of at least one key outcome were obtained from $>85 \%$ of subjects. (8) Data were analyzed by intention to treat. (9) Results reported for at least one key outcome. (10) Point measures and measures of variability provided.

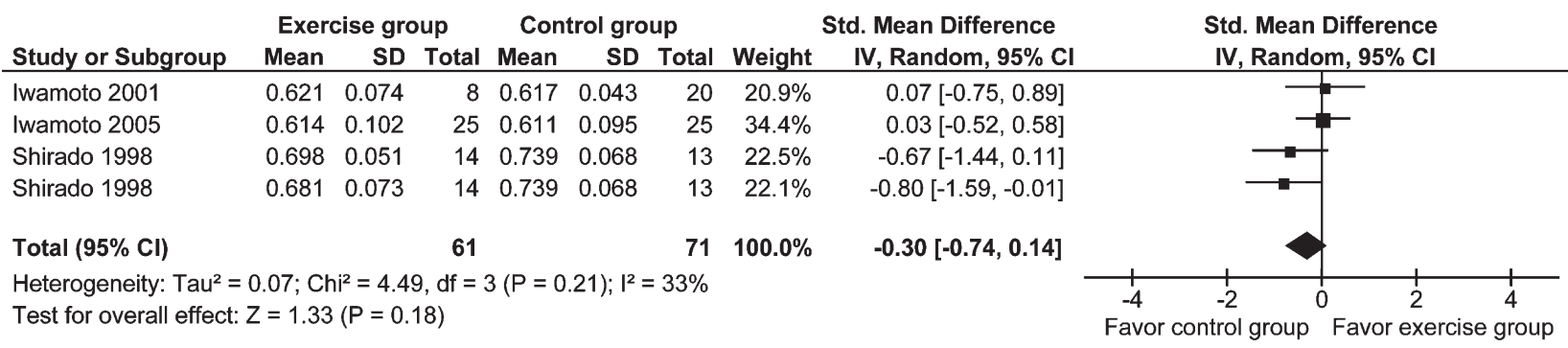

Fig. 2. Forest plot for RCTs regarding the effect of exercise intervention on BMD of the lumbar spine

Howe et al. ${ }^{7)}$ suggested a relatively small but statistically significant and possibly important effect of exercise on bone density compared with the findings for the control groups. In the current analysis, however, a positive effect of exercise intervention on lumbar BMD was not confirmed. These results are different from those of the Cochrane Review and another study that confirmed a positive effect for populations with OP in Western countries. Bergstorom et al. ${ }^{16)}$, who investigated exercise intervention of the same duration and frequency as used in the studies included in our review ${ }^{13-15)}$, showed a positive effect of exercise intervention on BMD. The dissimilarity between the results of Bergstorom et al. ${ }^{16)}$ and those ${ }^{13-15)}$ included in our review is the BMD at baseline. The BMD at baseline in the study of Bergstorom et al. ${ }^{16)}$ performed in Western countries was $0.88 \mathrm{~g} / \mathrm{cm}^{2}$. However, in the studies ${ }^{13-15)}$ of populations with OP in Japan, the lumbar BMD at baseline was less than $0.7 \mathrm{~g} / \mathrm{cm}^{2}$ in the exercise groups. The BMD of Japanese subjects with OP is apparently less than that of American or European subjects with OP. The bone metabolism of osteoporotic bone in response to mechanical stimuli is less active than that of healthy bone ${ }^{17)}$. Because of the low response of bone metabolism to mechanical stimuli, low BMD may contribute to the lack of an effect of exercise intervention on lumbar BMD in Japanese subjects.

In their systematic review and meta-analysis, Howe et al. reported that the most effective intervention for BMD of the spine was "combination exercise programs"7). According to them, combination exercise programs include static weightbearing exercises, dynamic weight-bearing exercises with low force, dynamic weight-bearing exercises with high force, non-weight-bearing exercises with low force or non-weight- bearing exercises with high force. The intervention method described in the study by Iwamoto et al. ${ }^{14)}$, one of the studies used in our study, could be categorized as a combination exercise program; their study reported no effect of the exercise program on BMD. Moreover, our results showed no significant heterogeneity between studies that had BMD as an outcome. At present, we cannot conclude that combination exercise programs are the most effective intervention for BMD in Japanese individuals with OP.

Frost ${ }^{18)}$ proposed the "mechanostat theory" to explain the mechanism of skeletal adaptation to mechanical stimulation; i.e., increased mechanical loading stimulates bone modeling and depresses bone remodeling. All 3 studies included in our study did not necessarily apply high-intensity exercises. In addition, it is widely accepted that the mean BMI of Western people is higher than that of Japanese. Even if Japanese subjects with OP performed high-intensity exercises, mechanical loading on the bone during exercises seems to be substantially less than that in American or European subjects. Taken together, the observation of no positive effects of any exercises on BMD in Japanese people may be attributed to insufficient mechanical loading on the joint and bone.

In Western countries, some studies reported the effect of exercise interventions on bone metabolic markers. Bjarnason et $\mathrm{al}^{4)}$. reported that 6- and 12-month changes in bone turnover were related to reductions in vertebral fracture risk during 3 years of raloxifene treatment in women with postmenopausal OP. Eastell et al. ${ }^{5)}$ confirmed the relationship of early changes in bone resorption with the reduction in fracture risk conferred by risedronate treatment. Judge et al. ${ }^{6}$ demonstrated that long-term moderate resis- 
tance training reversed bone loss, decreased bone turnover, increased femur BMD and maintained body composition. Among the various trials in Japanese subjects with OP, however, only 1 study $^{13}$ ) examined the effects of exercise intervention on bone metabolic markers. Iwamoto et al. ${ }^{13}$ reported no effect of whole-body vibration exercise on urinary NTX and serum ALP levels. The effect of exercise with vibration on bone metabolic markers was not observed in Japanese subjects with OP. To demonstrate the absolutely certain effect of exercise interventions on fall-related fracture risk factors in trials in Japanese individuals with OP, future research is needed to evaluate the effect of other exercise interventions on bone metabolism by using bone metabolic markers as biochemical parameters.

According to PRISMA ${ }^{19)}$, our systematic review and meta-analysis were performed correctly. However, our results should be interpreted cautiously. The included studies had a maximum PEDro score of 6 . Blinding of the therapist and participants is not possible for this type of study, where 8 points is the highest possible score. Even after considering this factor, however, the methodological quality of the studies included was not high. Two studies ${ }^{13,14)}$ did not perform adequate follow-up and intention-to-treat analysis. Therefore, the range of the evidence level produced in our review was from low to moderate. In particular, the evidence level for lumbar BMD was low. The results of systematic review of bone metabolic markers were confirmed for 1 study only. If the number of studies that examine the effect of exercise on these outcomes in Japanese subjects with OP increases in the future, a positive effect might be confirmed.

Martyn-St James et al. ${ }^{20)}$ assessed the effects of differing modes of impact exercise on bone density at the hip and spine in premenopausal women through a systematic review and meta-analysis. They synthesized the data of multiple studies involving dissimilar exercise interventions in detail. We followed their method and confirmed the lack of statistical heterogeneity in our meta-analysis. Although it may not be reasonable to include all studies in the same analysis, our results from a meta-analysis are consistent with the results of 3 trials showing no exercise effect on BMD. More studies which are similar in exercise interventions may be needed to reveal the range of the generalization.

Although there is evidence for the effectiveness of exercise intervention in the prevention of falls in populations with OP, the effect of such interventions in Japanese subjects with OP is less intensively studied. As a result, most exercise recommendations for Japanese patients with OP are based on studies conducted in Western countries. However, responses to exercise may differ between populations with OP in Western countries and those in Japan. Since Japanese patients with OP may have an altered response to exercise, recommendations on exercise for prevention of falls and fall-related fractures for Japanese populations should be made after referring to our results.

Some studies have shown that exercise intervention improves BMD in populations with low BMD in Western countries. However, in the present study, we could not show that BMD is improved in Japanese populations with OP by exercise intervention. The effects of exercise intervention on BMD may be moderated by the BMD of participants and exercise content (e.g., variety of exercise and exercise intensity). Future studies should use well-designed exercise interventions and identify the effect of exercise intervention on fracture risk in Japanese individuals with OP.

\section{REFERENCES}

1) World Health Organization: Assessment of fracture risk and its application to screening for postmenopausal osteoporosis: Report of a WHO Study Group. Geneva: WHO, 1994 (Technical Report Series 843). JAMA, 2001, 285: 785-795. [Medline]

2) Papaioannou A, Morin S, Cheung AM, et al.: 2010 clinical practice guidelines for the diagnosis and management of osteoporosis in Canada: summary. CMAJ, 2010, 182: 1864-1873. [Medline] [CrossRef]

3) Cummings SR, Black DM, Nevitt MC, et al.: Bone density at various sites for prediction of hip fractures. The Study of Osteoporotic Fractures Research Group. Lancet, 1993, 341: 72-75. [Medline] [CrossRef]

4) Bjarnason NH, Sarkar S, Duong T, et al.: Six and twelve month changes in bone turnover are related to reduction in vertebral fracture risk during 3 years of raloxifene treatment in postmenopausal osteoporosis. Osteoporos Int, 2001, 12: 922-930. [Medline] [CrossRef]

5) Eastell R, Barton I, Hannon RA, et al.: Relationship of early changes in bone resorption to the reduction in fracture risk with risedronate. J Bone Miner Res, 2003, 18: 1051-1056. [Medline] [CrossRef]

6) Judge JO, Kleppinger A, Kenny A, et al.: Home-based resistance training improves femoral bone mineral density in women on hormone therapy. Osteoporos Int, 2005, 16: 1096-1108. [Medline] [CrossRef]

7) Howe TE, Shea B, Dawson LJ, et al.: Exercise for preventing and treating osteoporosis in postmenopausal women. Cochrane Database Syst Rev, 2011, CD000333. [Medline]

8) Gregg EW, Pereira MA, Caspersen CJ: Physical activity, falls, and fractures among older adults: a review of the epidemiologic evidence. J Am Geriatr Soc, 2000, 48: 883-893. [Medline]

9) Murakami Y, Miura K, Ueshima H: Comparison of the trends and current status of obesity between Japan and other developed countries. Nihon Rinsho, 2009, 67: 245-252. [Medline]

10) De Laet C, Kanis JA, Oden A, et al.: Body mass index as a predictor of fracture risk: a meta-analysis. Osteoporos Int, 2005, 16: 1330-1338. [Medline] [CrossRef]

11) Maher CG, Sherrington $C$, Herbert RD, et al.: Reliability of the PEDro scale for rating quality of randomized controlled trials. Phys Ther, 2003, 83: 713-721. [Medline]

12) Deeks JJ, Higgins JP, Altman DG: Analysing data and undertaking metaanalyses. In: Higgins JPT and Green S (eds): Cochrane Handbook for Systematic Reviews of Interventions. West Sussex: Wiley-Blackwell, 2008, pp 243-296.

13) Iwamoto J, Takeda T, Sato $Y$, et al.: Effect of whole-body vibration exercise on lumbar bone mineral density, bone turnover, and chronic back pain in post-menopausal osteoporotic women treated with alendronate. Aging Clin Exp Res, 2005, 17: 157-163. [Medline]

14) Iwamoto J, Takeda $T$, Ichimura $S$ : Effect of exercise training and detraining on bone mineral density in postmenopausal women with osteoporosis. J Orthop Sci, 2001, 6: 128-132. [Medline] [CrossRef]

15) Shirado O, Ito $T$, Kaneda $K$ The effect of exercise on postmenopausal osteoporosis. Bessatsu Seikeigeka. 1998, 33: 82-86 (in Japanese).

16) Bergström I, Brinck J, Saaf M: Effects of physical training on bone mineral density in fertile women with idiopathic osteoporosis. Clin Rheumatol, 2008, 27: 1035-1038. [Medline] [CrossRef]

17) Sterck JG, Klein-Nulend J, Lips P, et al.: Response of normal and osteoporotic human bone cells to mechanical stress in vitro. Am J Physiol, 1998, 274: E1113-E1120. [Medline]

18) Frost HM: The role of changes in mechanical usage set points in the pathogenesis of osteoporosis. J Bone Miner Res, 1992, 7: 253-261. [Medline] [CrossRef]

19) Liberati A, Altman DG, Tetzlaff J, et al.: The PRISMA statement for reporting systematic reviews and meta-analyses of studies that evaluate health care interventions: explanation and elaboration. PLoS Med, 2009, 6: e1000100. [Medline] [CrossRef]

20) Martyn-St James M, Carroll S: Effects of different impact exercise modalities on bone mineral density in premenopausal women: a meta-analysis. J Bone Miner Metab, 2010, 28: 251-267. [Medline] [CrossRef] 